Wright State University

CORE Scholar

Physics Faculty Publications

Physics

$5-4-2009$

\title{
Metal Contacts on Bulk ZnO Crystal Treated with Remote Oxygen Plasma
}

Z-Q. Fang

B. Claflin

David C. Look

Wright State University - Main Campus, david.look@wright.edu

Y. F. Dong

L. Brillson

Follow this and additional works at: https://corescholar.libraries.wright.edu/physics

Part of the Physics Commons

\section{Repository Citation}

Fang, Z., Claflin, B., Look, D. C., Dong, Y. F., \& Brillson, L. (2009). Metal Contacts on Bulk ZnO Crystal Treated with Remote Oxygen Plasma. Journal of Vacuum Science \& Technology B, 27 (3), 1774-1779. https://corescholar.libraries.wright.edu/physics/7

This Article is brought to you for free and open access by the Physics at CORE Scholar. It has been accepted for inclusion in Physics Faculty Publications by an authorized administrator of CORE Scholar. For more information, please contact library-corescholar@wright.edu. 


\title{
Metal contacts on bulk $\mathrm{ZnO}$ crystal treated with remote oxygen plasma
}

\author{
Z.-Q. Fang, ${ }^{\text {a) }}$ B. Claflin, and D. C. Look \\ Semiconductor Research Center, Wright State University, Dayton, Ohio 45435 \\ Y.-F. Dong and L. Brillson \\ Department of Electrical and Computer Engineering, The Ohio State University, Columbus, Ohio 43210
}

(Received 21 November 2008; accepted 11 February 2009; published 29 May 2009)

\begin{abstract}
To study the quality of thin metal/ZnO Schottky contacts (SCs), temperature-dependent current-voltage $(I-V)$, capacitance-voltage, deep level transient spectroscopy, and photoluminescence measurements were performed using bulk, vapor-phase $\mathrm{ZnO}$, treated by remote oxygen plasma (ROP). $\mathrm{Au} / \mathrm{ZnO}$ and $\mathrm{Pd} / \mathrm{ZnO}$ contacts on both $\mathrm{O}$ and $\mathrm{Zn}$ faces are compared as a function of the ROP processing sequence and duration. We find that (i) as the duration of ROP treatment increases from 2 to $4 \mathrm{~h}, \mathrm{Au} / \mathrm{ZnO}$ contacts on the $\mathrm{Zn}$ face, deposited before $R O P$ treatment, become rectifying, while those on the $\mathrm{O}$ face remain Ohmic; (ii) with long-term ROP treatments prior to metallization, both $\mathrm{Au} / \mathrm{ZnO}$ and $\mathrm{Pd} / \mathrm{ZnO}$ show high-quality SCs; however, their $I-V$ characteristics can be significantly degraded by electric field and high temperatures; (iii) ROP treatment can cause more $\mathrm{H}$ removal on the $\mathrm{Zn}$ face than on the $\mathrm{O}$ face, resulting in a decrease in the near-surface carrier concentration for the $\mathrm{Zn}$ face only; (iv) in addition to the dominant bulk-trap E3, surface traps, E6/E7 and E8, and Es, can be observed in $\mathrm{Au} / \mathrm{ZnO}$ and $\mathrm{Pd} / \mathrm{ZnO} \mathrm{SCs}$, respectively, on the $\mathrm{Zn}$ face, with shorter ROP treatment; and (v) with long-term ROP treatment, E3 (or L2) significantly increases and shifts in Au/ZnO SCs on the Zn face. (C) 2009 American Vacuum Society. [DOI: 10.1116/1.3095814]
\end{abstract}

\section{INTRODUCTION}

To realize the potential of high-performance $\mathrm{ZnO}$-based optical and electronic devices, the formation of high-quality metal/ZnO Schottky contacts (SCs) is essential. Surface preparation prior to metal deposition is also important, and remote oxygen plasma (ROP) treatment has been found to be very effective to remove surface adsorbates and defects and to form good SCs. ${ }^{1}$ The effects of near-surface or nearinterface defects on the quality of $\mathrm{ZnO}$ Schottky barriers and $\mathrm{Zn}$ - and O-face polarity effects have been well characterized by applying depth-resolved cathodoluminescence spectroscopy (DRCLS) in conjunction with current-voltage $(I-V)$ and capacitance-voltage $(C-V)$ measurements. ${ }^{2,3}$ In addition to these optical studies, deep level transient spectroscopy (DLTS) has been used to observe a surface trap, Es $(0.49 \mathrm{eV})$, in bulk vapor-phase (VP) grown $\mathrm{ZnO}$, in addition to the well-known bulk traps E3 and E4. ${ }^{4}$ In this work, we perform temperature-dependent $I-V, C$ - $V$, DLTS, and photoluminescence (PL) measurements on thin metal/ZnO SCs and $\mathrm{ZnO}$ surfaces. We compare $\mathrm{Au}$ and $\mathrm{Pd} \mathrm{SCs}$, on both the $\mathrm{Zn}$ and $\mathrm{O}$ faces, as a function of the duration of ROP treatment. We will present (i) temperature-dependent $I-V$ characteristics of Au contacts, on both the $\mathrm{Zn}$ and $\mathrm{O}$ faces, deposited before and after ROP treatment; (ii) enhanced degradation of the $I-V$ characteristics for Au and Pd SCs, by electric field and temperature; (iii) effects of ROP treatment and surface polarity on carrier concentration profiles in the SCs and hydrogen removal; and (iv) the effects of the ROP-

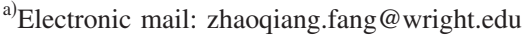

treatment duration and surface polarity on electrical properties of the Au and Pd SCs, bulk traps E3 and E4, and surface traps E6/E7 and E8

\section{SAMPLE PREPARATION AND EXPERIMENT}

Bulk, VP, ZnO samples grown by ZN Technology, Inc., which were chemomechanically polished on both (0001) Zn and (000-1) $\mathrm{O}$ faces, were used in this study. These samples typically exhibit room temperature (RT) carrier concentrations in the mid-to-high $10^{16} \mathrm{~cm}^{-3}$ range and a mobility of $\sim 220 \mathrm{~cm}^{2} / \mathrm{V} \mathrm{s}$. To compare the effect of surface polarity, 5 $\times 5 \mathrm{~mm}^{2}$ samples were cut in half, and oriented with O- and $\mathrm{Zn}$-face up, respectively. The samples were cleaned with organic solvents and loaded into an ultrahigh vacuum chamber (base pressure of $\sim 5 \times 10^{-9}$ Torr) and processed with room temperature ROP $\left(20 \% \mathrm{O}_{2}-80 \% \mathrm{He}\right.$ and power of $\left.40 \mathrm{~W}\right)$ treatment for 1, 2, or $4 \mathrm{~h}$. Arrays of $\mathrm{Au}$ and Pd contacts (30 nm thick and $0.4 \mathrm{~mm}$ in diameter) were deposited in situ on the ROP-treated $\mathrm{ZnO}$ surfaces by electron beam evaporation using a removable mask. Au contacts were also deposited on the $\mathrm{ZnO}$ surfaces prior to ROP treatment. Thus, rectification of the Au contacts, deposited before and after the ROP treatment, can be compared. Finally, the back side of each sample was covered with a 40/60/30 nm Ohmic $\mathrm{Ti} / \mathrm{Ni} / \mathrm{Au}$ contact by e-beam evaporation. For the $I-V$ and $C-V$ measurements, Au probes were used to investigate individual $\mathrm{Au}$ and Pd contacts on the top surface. The $C-V$ and DLTS measurements were performed with an Accent DL8000 spectrometer, operated at a frequency of $1 \mathrm{MHz}$. The $I-V$ measurement was carried out with a current amplifier in the spectrometer. Carrier concentration profiles were determined from bias-dependent $C$ - $V$ data and the DLTS 

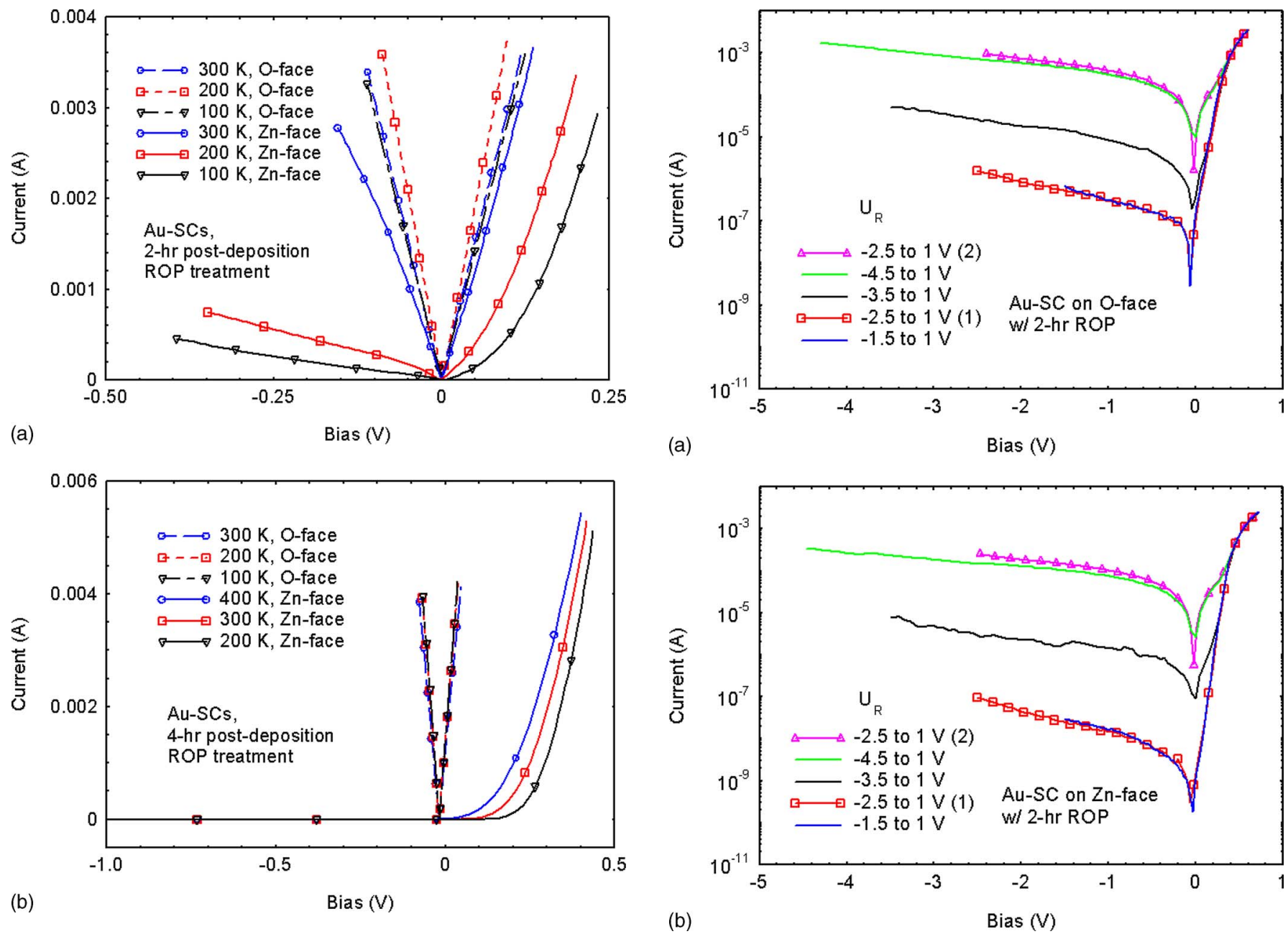

FIG. 1. (Color online) Temperature-dependent $I$ - $V$ characteristics, measured for $\mathrm{Au}$ contacts on $\mathrm{O}$ face and $\mathrm{Zn}$ face, with post deposition ROP treatment for (a) $2 \mathrm{~h}$ and (b) $4 \mathrm{~h}$.

spectra were obtained from the Fourier transforms of capacitance transients as temperature was swept between 100 and $400 \mathrm{~K}$. We used a technique that was developed previously to determine whether a particular trap originates in the bulk or near-surface regions. ${ }^{5}$ The DLTS spectrum is measured for different values of reverse bias while keeping the filling pulse height fixed. With increasing reverse bias (i.e., more negative value), the DLTS signal will increase for a bulk trap or decrease for a near-surface trap. PL at $4.2 \mathrm{~K}$ was measured on both $\mathrm{O}$ and $\mathrm{Zn}$ faces of the $\mathrm{ZnO}$ samples with different treatment durations of ROP using $325 \mathrm{~nm}$ line of a $\mathrm{He}-\mathrm{Cd}$ laser.

\section{RESULTS AND DISCUSSION}

\section{A. Rectification and degradation of the $I-V$ characteristics}

Temperature-dependent $I-V$ characteristics for Au contacts, deposited on the $\mathrm{O}$ and $\mathrm{Zn}$ faces and subjected to postdeposition ROP treatments for 2 or $4 \mathrm{~h}$, are shown in Figs. 1(a) and 1(b), respectively. Both Au contacts on the $\mathrm{O}$ face are Ohmic at all temperatures. In contrast, the Au contact on

FIG. 2. (Color online) $I-V$ characteristics, measured as a function of starting bias for $\mathrm{Au}-\mathrm{SCs}$ on (a) $\mathrm{O}$ face and (b) $\mathrm{Zn}$ face, with $2 \mathrm{~h}$ prior-deposition ROP treatment. Curves (1) and (2) were measured under voltage swept from -2.5 to $1 \mathrm{~V}$, following measurements at starting bias of -1.5 and $-4.5 \mathrm{~V}$, respectively.

the $\mathrm{Zn}$ face, with $2 \mathrm{~h}$ postdeposition ROP, is Ohmic only at $300 \mathrm{~K}$ and becomes rectifying at lower temperatures. However, the Au contact on the $\mathrm{Zn}$ face, with $4 \mathrm{~h}$ postdeposition ROP treatment exhibits good rectifying ratios at all temperatures. On the other hand, likely because of the removal of $\mathrm{OH}$ radicals and adsorbed carbon, ${ }^{1}$ Au contacts deposited after ROP treatment are good SCs. Both reverse and forward currents of these SCs decrease with increasing duration of the ROP treatment, especially those on the $\mathrm{Zn}$ face [compare $I-V$ curves measured at lower biases in Figs. 2(a) and 2(b)]. We checked the stability of the $I-V$ characteristics for these $\mathrm{Au}-\mathrm{SCs}$ at $300 \mathrm{~K}$ and found significant electric-fieldenhanced degradation. $300 \mathrm{~K} \mathrm{I-V}$ curves of Au-SCs on the O and $\mathrm{Zn}$ faces, both with $2 \mathrm{~h}$ ROP treatment, measured as a function of initial bias $\left(U_{R}\right)$, are pictured in Figs. 2(a) and 2(b), respectively. It is clearly seen that for Au-SCs on $\mathrm{O}$ and $\mathrm{Zn}$ faces, (i) for measurements started at $U_{R}=-1.5$ or $-2.5 \mathrm{~V}$, the $I-V$ curves were not affected by $U_{R}$, (ii) as the initial value of $U_{R}$ increases from -2.5 to $-4.5 \mathrm{~V}$, both the reverse and forward currents increase, and (iii) a permanent 

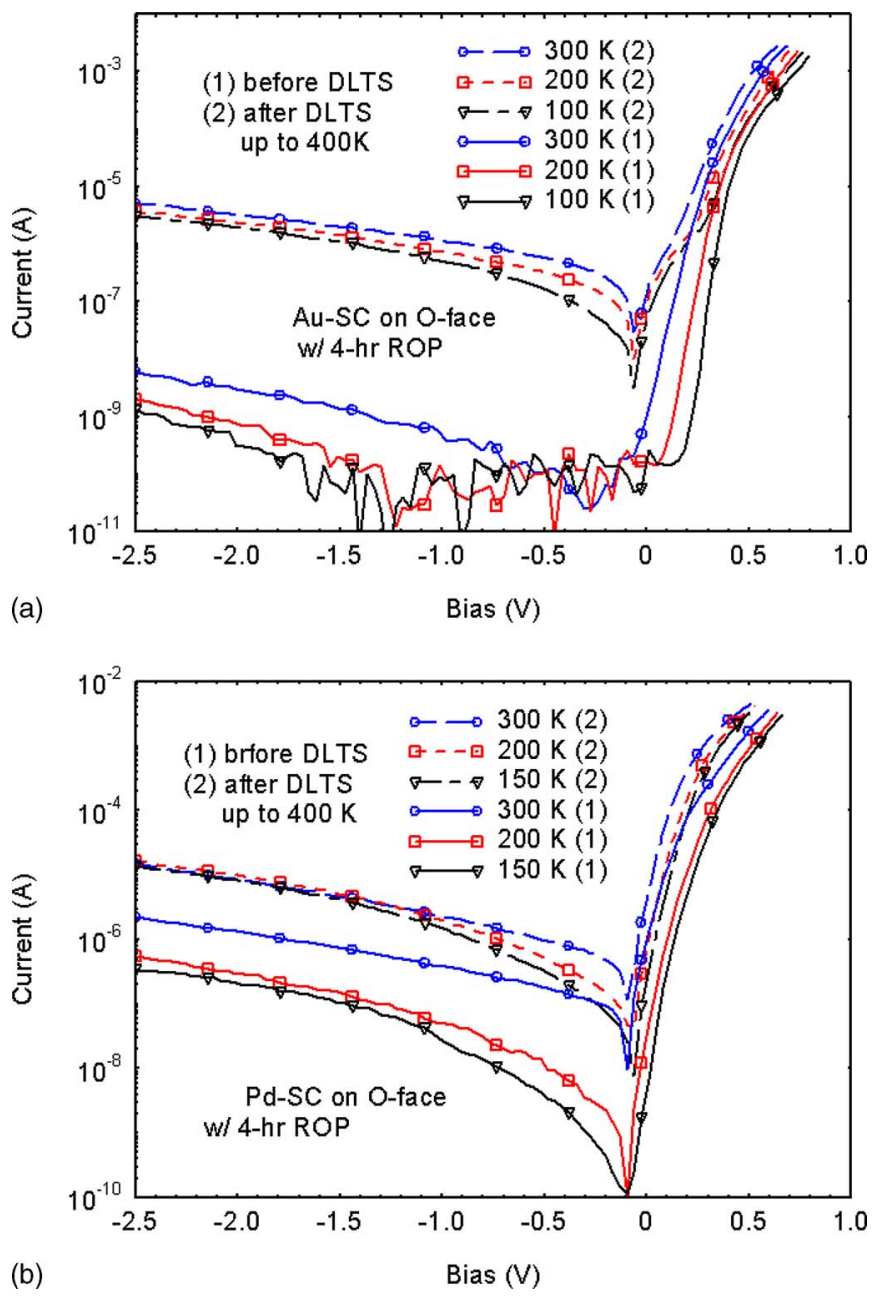

FIG. 3. (Color online) Temperature-dependent $I-V$ characteristics, measured before and after DLTS measurements, for (a) Au-SC and (b) Pd-SC on O face, with $4 \mathrm{~h}$ ROP treatment.

increase of the forward and reverse currents was observed for $I-V$ measurements starting at $U_{R}=-2.5 \mathrm{~V}$ following measurement initiated at $U_{R}=-4.5 \mathrm{~V}$. Since $C-V$ characteristics and carrier concentration profiles at $300 \mathrm{~K}$ do not change in the measurements until the initial value of $U_{R}$ increases to $-4.5 \mathrm{~V}$ (not shown here), we believe that the increased currents probably flow through localized current paths.

In general, the electrical quality of Pd-SCs was found to be poorer than that of Au-SCs, possibly due to higher carrier concentrations in the former caused by hydrogen diffusion through the thin Pd layers. ${ }^{3,4}$ Electric-field-enhanced degradation was also observed on Pd-SCs on both $\mathrm{O}$ and $\mathrm{Zn}$ faces, with 2 h ROP treatment (not shown here). Degradation of the $I-V$ characteristics, produced by exposure to high temperatures, for both Au- and Pd-SCs, was often found after DLTS measurements up to $400 \mathrm{~K}$, as shown in Figs. 3(a) and 3(b), respectively. In Fig. 3(a), very good quality Au-SCs, with leakage currents of $10^{-9}-10^{-8} \mathrm{~A}$ at $U_{R}=-2.5 \mathrm{~V}$, are observed in the first measurements after mounting the sample in vacuum. However, after subsequent DLTS measurements up to $400 \mathrm{~K}$, the Au-SC degrades, with the leakage currents increasing to $10^{-6}-10^{-5} \mathrm{~A}$. The forward currents at lower

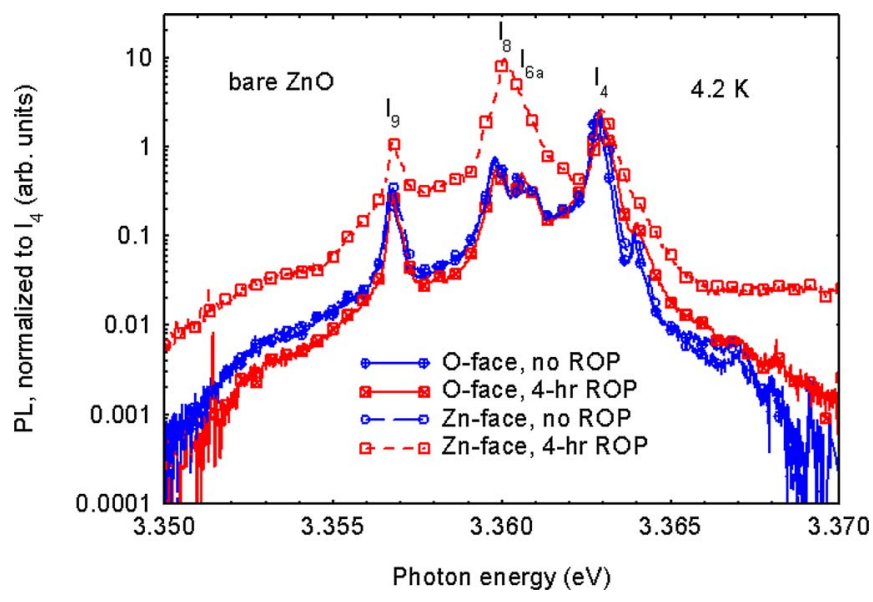

FIG. 4. (Color online) Normalized 4.2 K PL spectra measured on $\mathrm{O}$ face and $\mathrm{Zn}$ face, with 0 or $4 \mathrm{~h}$ ROP treatment.

biases are also affected. Similarly, in Fig. 3(b), the Pd-SC initially is fairly good, with leakage currents of $3 \times 10^{-7}-2$ $\times 10^{-6} \mathrm{~A}$ at $U_{R}=-2.5 \mathrm{~V}$, but degrades, with leakage currents of $\sim 10^{-5} \mathrm{~A}$, after subsequent DLTS measurements. As compared to the data measured before DLTS, the $I-V$ characteristics measured after DLTS show much less temperature dependence, indicating possible tunneling conduction or the presence of localized current paths.

Observations of the Ohmic-Schottky conversion, facilitated by an increase in the postdeposition ROP duration, and the degradation of the $I-V$ characteristics, enhanced by electric field and high temperatures imply that a mobile species, such as hydrogen, might play an important role in the formation of high-quality metal/ZnO SCs. Hydrogen incorporation by the application of electrical current (under higher voltage sweep) in annealed hydrothermal $\mathrm{ZnO}$ has been reported. ${ }^{6}$ Degradation of the $I-V$ characteristics following DLTS measurements (up to $400 \mathrm{~K}$ ) could be accelerated by long-term current-driven hydrogen incorporation at high temperatures. Indeed, bulk hydrogen was detected in our VP-ZnO samples, as described below.

\section{B. Photoluminescence and carrier concentration profiles}

PL spectra measured at $4.2 \mathrm{~K}$ on the $\mathrm{O}$ and $\mathrm{Zn}$ faces, for untreated samples or those that received a $4 \mathrm{~h}$ ROP treatment, are shown in Fig. 4. Donor bound exciton lines, $I_{4}$ $(3.3628 \mathrm{eV}), \quad I_{6 a}(3.3604 \mathrm{eV}), \quad I_{8}(3.3598 \mathrm{eV})$, and $I_{9}$ $(3.3567 \mathrm{eV})$, have been identified using the spectral positions published by Meyer et al. ${ }^{7}$ The lines $I_{4}, I_{6 a}, I_{8}$, and $I_{9}$ are assigned to $\mathrm{H}, \mathrm{Al}, \mathrm{Ga}$, and In, respectively. It should be noted that (i) the two PL spectra for $\mathrm{O}$ and $\mathrm{Zn}$ faces, without ROP treatment, are almost identical and are dominated by $I_{4}(\mathrm{H}$ donor), (ii) the $4 \mathrm{~h}$ ROP treatment on the $\mathrm{O}$ face did not produce any meaningful change in PL features ( $\mathrm{H}$ donor still dominant), and (iii) the $4 \mathrm{~h}$ ROP treatment on the $\mathrm{Zn}$ face did cause a significant increase in the relative peak intensities of $I_{8}$ and $I_{6 a}$ over $I_{4}$. These results reveal a reduction in nearsurface $\mathrm{H}$ donors (i.e., $\mathrm{H}$ removal) by ROP treatment on the 


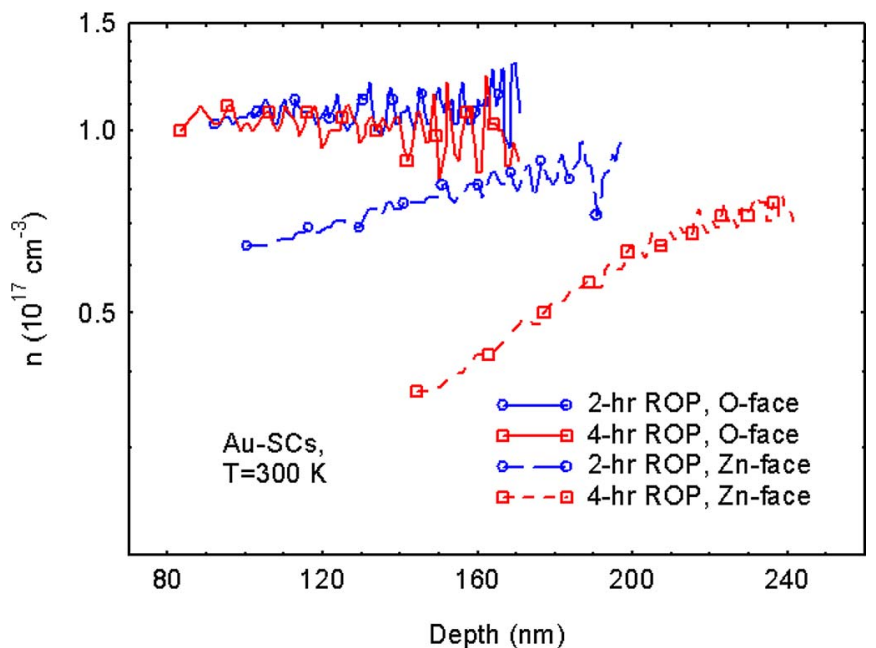

FIG. 5. (Color online) Carrier concentration profiles for Au-SCs on O-face and $\mathrm{Zn}$ face, with 2 or $4 \mathrm{~h}$ ROP treatment.

Zn face (similar to observations in a previous report ${ }^{1}$ ), but not on the $\mathrm{O}$ face. Interestingly, carrier concentration profiles, deduced from $C-V$ measurements with $U_{R}$ swept from -2.5 to $0 \mathrm{~V}$, behave differently for Au-SCs on the two polar faces for different durations of ROP treatment. As shown in Fig. 5, Au-SCs on the $\mathrm{O}$ face that were exposed to ROP for 2 or $4 \mathrm{~h}$ exhibit almost identical, flat carrier concentrations profiles of $\sim 1 \times 10^{17} \mathrm{~cm}^{-3}$. However, carrier concentration profiles for $\mathrm{Au}-\mathrm{SC}$ s on the $\mathrm{Zn}$ face were found to decrease towards the surface with a larger decrease seen for longer ROP treatment. This sharp contrast in carrier concentration profiles (flat on $\mathrm{O}$ face versus a decrease in the $\mathrm{Zn}$ face with a larger drop for longer ROP treatment) was also found in the Pd-SCs (not shown). We believe that the decrease of carrier concentration on the $\mathrm{Zn}$ face with increasing ROP-treatment duration is mainly due to $\mathrm{H}$ removal, consistent with the observation of a ROP-induced reduction in $I_{4}$. It seems that there exits a barrier on the $\mathrm{O}$ face to prevent hydrogen outdiffusion. Further study is needed to understand the mechanism of the $\mathrm{H}$ removal from $\mathrm{ZnO}$ by ROP treatment at $\mathrm{RT}$ and the difference between the two polarities.

\section{Observation of surface traps on $\mathrm{Zn}$ face}

DLTS spectra measured at different reverse bias $\left(U_{R}\right)$ values for Au-SCs on the $\mathrm{Zn}$ face, with different ROP treatments, are shown in Figs. 6(a) and 6(b), respectively. Figure 6(a) compares DLTS spectra for Au-SCs deposited before or after a $4 \mathrm{~h}$ ROP treatment. As $U_{R}$ increases from -0.25 to $-1.5 \mathrm{~V}$, the trap E3 increases (for both ROP treatments), indicating its bulk nature. However, the Au-SC deposited before the $4 \mathrm{~h}$ ROP (having only a postdeposition ROP treatment, i.e., less ROP), shows strong traps E6/E7, which must be surface-related because they significantly decrease as $U_{R}$ is made increasingly negative. The $U_{R}$ dependence indicates that these traps are confined to a depth less than about $90 \mathrm{~nm}$ below the $\mathrm{Au} / \mathrm{ZnO}$ interface. Furthermore, the DLTS signal of traps E6/E7 depends strongly on filling pulse width (not
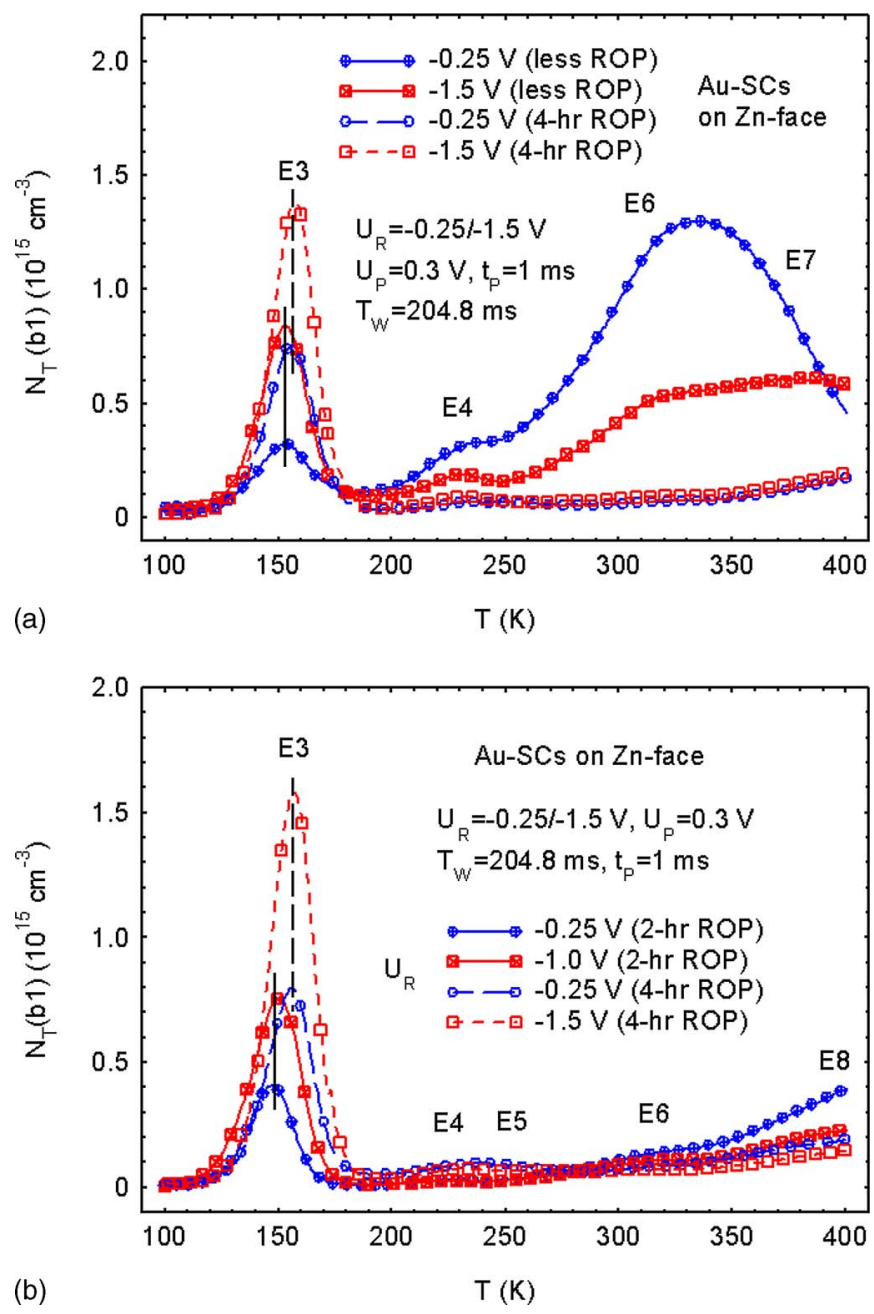

FIG. 6. (Color online) DLTS spectra, measured as a function of $U_{R}$, for $\mathrm{Au}-\mathrm{SCs}$ on $\mathrm{Zn}$ face, with (a) post-deposition (or less) ROP vs $4 \mathrm{~h}$ ROP and (b) $2 \mathrm{~h}$ ROP vs $4 \mathrm{~h}$ ROP. Measurement conditions: reverse bias $U_{R}=$ $-0.25 /-1.5 \mathrm{~V}$; filling pulse height $U_{P}=0.3 \mathrm{~V}$; filling pulse width $t_{P}=1 \mathrm{~ms}$; and transient period $T_{W}=205 \mathrm{~ms}$.

shown), indicating their association with extended defects [similar to the case of Es (Ref. 4)]. Figure 6(b) shows a comparison of DLTS spectra for Au-SCs, deposited after either a $2 \mathrm{~h}$ or $4 \mathrm{~h}$ ROP treatment. Again, observing the dependence of signal strength on $U_{R}$ we find that the dominant E3 trap is bulklike for both Au-SCs. In addition, for both Au-SCs, a surface trap E8 peaked at $T \geqslant 400 \mathrm{~K}$ is observed. With increasing ROP duration, E8 becomes weaker. For Pd$\mathrm{SC}$ s on the $\mathrm{Zn}$ face, we see a similar behavior. For a $1 \mathrm{~h}$ ROP, a surface trap Es is observed, ${ }^{4}$ while for a 2 h ROP, Es disappears, leaving a larger E3 peak and a very weak E4 trap (not shown). As reported previously, ${ }^{4}$ Es $(0.49 \mathrm{eV})$ is located at depths less than about $95 \mathrm{~nm}$ below the $\mathrm{Pd} / \mathrm{ZnO}$ interface and shows an electron capture behavior indicative of extended defects. Thus, from the comparisons presented above, we can conclude that a long ROP treatment is effective at removing extended-defect-related surface traps on the $\mathrm{Zn}$ face of $\mathrm{ZnO}$. It is interesting to note that E3 can be affected by the ROP treatment. With increasing duration of the ROP treatment, the trap density of E3 increases by approximately 
two times, and its peak shifts to higher temperatures by a few degrees (sometimes $\sim 10 \mathrm{~K}$ ). According to previous DLTS studies on bulk $\mathrm{ZnO},{ }^{8-10} \mathrm{E} 3$ (or L2), with $E_{T}$ $=0.28-0.32 \mathrm{eV}$, has tentatively been assigned to a defect related to oxygen vacancies $\left(V_{\mathrm{O}}\right)$. Since the ROP treatment causes significant $\mathrm{H}$ removal on the $\mathrm{Zn}$ face, we speculate that (i) there might exist complexes of $V_{\mathrm{O}}$ with $\mathrm{H}$ in the surface region of $\mathrm{VP}-\mathrm{ZnO}$, and (ii) the increase in $\mathrm{E} 3$ might result from the dissociation of the $V_{\mathrm{O}}-\mathrm{H}$ complexes. The peak temperature shift of E3 might be related to the electricfield related Poole-Frenkel effect. As seen in Fig. 5, the carrier concentration in the near-surface region on the $\mathrm{Zn}$ face decreases with increasing ROP duration. This decrease in carrier concentration can lead to a lower electric field in the depletion region, resulting in a shift of E3 to higher temperatures. However, in addition to the commonly observed trap E3 $(0.3 \mathrm{eV})$, another close lying peak E3' $(0.37 \mathrm{eV})$ was reported by using high resolution Laplace-transform DLTS in $\mathrm{ZnO}$ grown by pulsed-laser deposition. ${ }^{11}$ An increase in the concentration of E3' after annealing in oxygen suggested that this new trap could be associated with oxygen incorporation. In that study, however, E3' was not found in any bulk-grown $\mathrm{ZnO}$ (serving as a reference). Here, we cannot rule out that the increase and shift of E3 observed in the Au-SCs, with $4 \mathrm{~h}$ ROP treatment, could be due to existence of E3' since more oxygen can be produced by a ROP treatment. Further study would be needed to determine whether or not there really exists an E3/E3' feature in vapor-phase grown $\mathrm{ZnO}$ treated by long-term ROP.

\section{Observation of traps on $\mathrm{O}$ face}

Here, we present the effects of ROP on the traps in the $\mathrm{SCs}$ on the $\mathrm{O}$ face. DLTS spectra measured at different reverse bias $\left(U_{R}\right)$ values for Au- and Pd-SCs with $2 \mathrm{~h}$ and $4 \mathrm{~h}$ ROP treatments, are shown in Figs. 7(a) and 7(b), respectively. For the Au-SC, with a $2 \mathrm{~h}$ ROP treatment, we observe traps E3, E4, E5, E6, and E8, which are all bulk traps. However, for the $4 \mathrm{~h}$ ROP treated Au-SC, we find an increase in E3 and the appearance of surface trap E8. Since the carrier concentrations in the near-surface region for both ROP treatments are about the same (Fig. 5), there is little electric-field related shift of E3. In both $\mathrm{Pd}-\mathrm{SCs}$ [Fig. 7(b)], we observe E3, E4, E6, and E8, which are all bulk traps. However, in the $\mathrm{Pd}-\mathrm{SC}$, with a $4 \mathrm{~h}$ ROP treatment, we find an increase in E4, E6, and E8, but not in E3. The trap densities of E3 in the $\mathrm{Pd}$-SCs appear to be lower than those in the Au-SCs, which could be related to the higher carrier concentrations in the near-surface region for the Pd-SCs. Once again, the electricfield related shift of E3 is not significant, because of the flat carrier concentration profiles. Or, there might exist much less E3' in the SCs on the O face. By using the "maximum evaluation" method, the activation energies and capture cross sections for traps E3, E4, and E6 in the Pd-SC were determined
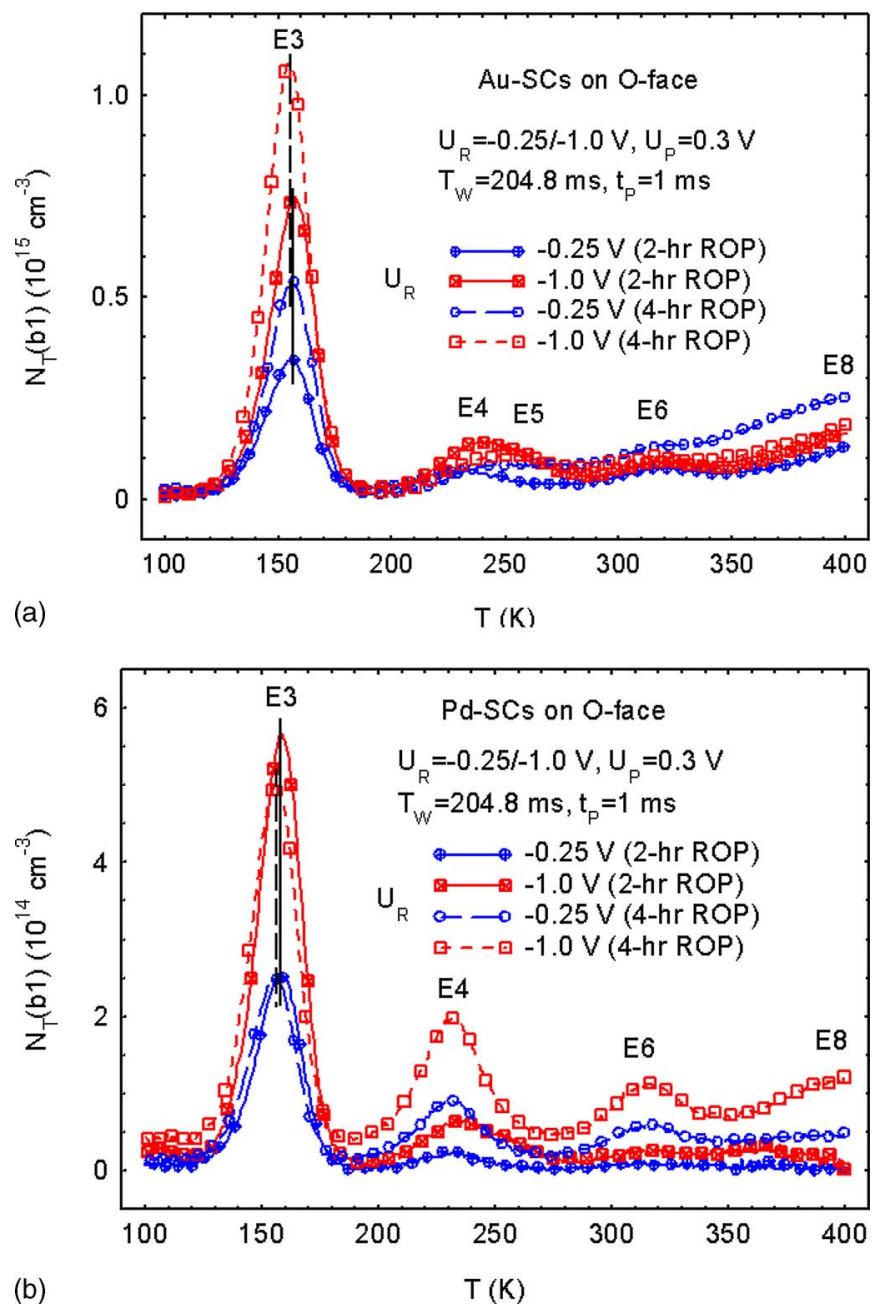

FIG. 7. (Color online) DLTS spectra measured as a function of $U_{R}$ for (a) $\mathrm{Au}-\mathrm{SCs}$ and (b) Pd-SCs on $\mathrm{O}$ face with 2 or $4 \mathrm{~h}$ ROP treatments. Measurement conditions: reverse bias $U_{R}=-0.25 /-1.0 \mathrm{~V}$; filling pulse height $U_{P}$ $=0.3 \mathrm{~V}$; filling pulse width $t_{P}=1 \mathrm{~ms}$; and transient period $T_{W}=205 \mathrm{~ms}$.

to be $0.22 \mathrm{eV}$ and $1.2 \times 10^{-17} \mathrm{~cm}^{2} ; \quad 0.49 \mathrm{eV}$ and 2 $\times 10^{-15} \mathrm{~cm}^{2}$; and $0.71 \mathrm{eV}$ and $5 \times 10^{-15} \mathrm{~cm}^{2}$, respectively.

\section{CONCLUSIONS}

To study the quality of thin metal/ZnO SCs, temperaturedependent $I-V, C-V$, DLTS, and PL measurements were performed, using bulk, VP ZnO samples, treated by ROP. We have compared $\mathrm{Au}$ - and $\mathrm{Pd}-\mathrm{SC}$, on both $\mathrm{O}$ and $\mathrm{Zn}$ faces, as a function of the ROP processing sequence and duration. It is found that (i) as ROP-treatment duration increases from 2 to $4 \mathrm{~h}, \mathrm{Au} / \mathrm{ZnO}$ contacts deposited on the $\mathrm{Zn}$ face without pre-ROP treatment, become rectifying, while those on $\mathrm{O}$-face remain ohmic; (ii) long-term ROP treatments prior to metallization, produce high-quality $\mathrm{Au} / \mathrm{ZnO}$ and $\mathrm{Pd} / \mathrm{ZnO} \mathrm{SCs}$; however, degradation of their $I-V$ characteristics can be significantly enhanced by electric-field and high-temperatures; (iii) ROP-treatment promotes more $\mathrm{H}$ removal on the $\mathrm{Zn}$ face than on the $\mathrm{O}$ face, resulting in a decrease in carrier concentration towards the surface on $\mathrm{Zn}$ face; (iv) surface traps, E6/E7 and E8, and Es, can be observed in $\mathrm{Au} / \mathrm{ZnO}$ and 
$\mathrm{Pd} / \mathrm{ZnO} \mathrm{SCs}$, respectively, on the $\mathrm{Zn}$ face, for shorter ROP treatments; and (v) long-term ROP treatment significantly increases and shifts $\mathrm{E} 3$ (or L2) for $\mathrm{Au} / \mathrm{ZnO} \mathrm{SCs}$ on the $\mathrm{Zn}$ face.

Further study is needed to correlate these surface traps with deep level defects (such as the 2.45- eV "green band") observed in the surface region by DRCLS.

\section{ACKNOWLEDGMENTS}

The authors wish to thank W. Rice for the photoluminescence measurements. Support of Z-QF, BC, and DCL was provided by DOE Grant DE-FG02-07ER46389 (R. Kortan), ARO Grant W911NF-07-D-0001/Task07275 (M. Gerhold), AFOSR Grant FA9550-07-1-0013 (K. Reinhardt), and AFRL Contract FA8650-06-D-5401 (D. Silversmith). Both the Ohio State and Wright State groups gratefully acknowledge support by NSF Grant DMR0513968 (L. Hess).
${ }^{1}$ H. L. Mosbacker, Y. M. Strzhemechny, B. D. White, P. E. Smith, D. C. Look, D. C. Reynolds, C. W. Litton, and L. J. Brillson, Appl. Phys. Lett. 87, 012102 (2005).

${ }^{2}$ L. J. Brillson, H. L. Mosbacker, M. J. Hetzer, Y. Strzhemechny, G. H. Jessen, D. C. Look, G. Cantwell, J. Zhang, and J. J. Song, Appl. Phys. Lett. 90, 102116 (2007)

${ }^{3}$ Y. Dong, Z.-Q. Fang, D. C. Look, G. Cantwell, J. Zhang, J. J. Song, and L. J. Brillson, Appl. Phys. Lett. 93, 072111 (2008).

${ }^{4}$ Z.-Q. Fang, B. Claflin, D. C. Look, Y. F. Dong, H. L. Mosbacker, and L. J. Brillson, J. Appl. Phys. 104, 063707 (2008).

${ }^{5}$ D. C. Look and Z.-Q. Fang, Appl. Phys. Lett. 79, 84 (2001).

${ }^{6}$ M.-S. Oh, D.-K. Hwang, J.-H. Lim, Y.-S. Choi, and S.-J. Park, Appl. Phys. Lett. 91, 212102 (2007)

${ }^{7}$ B. K. Meyer, J. Sann, D. M. Hofmann, C. Neumann, and A. Zeuner, Semicond. Sci. Technol. 20, S62 (2005).

${ }^{8}$ J. C. Simpson and J. F. Cordaro, J. Appl. Phys. 63, 1781 (1988).

${ }^{9}$ F. D. Auret, S. A. Goodman, M. J. Legodi, W. E. Meyer, and D. C. Look, Appl. Phys. Lett. 80, 1340 (2002).

${ }^{10}$ H. von Wenckstern, H. Schmidt, M. Grundmann, M. W. Allen, P. Miller, R. J. Reeve, and S. M. Durbin, Appl. Phys. Lett. 91, 022913 (2007).

${ }^{11}$ F. D. Auret, W. E. Meyer, P. J. Janse van Rensburg, M. Hayes, J. M. Nel, H. von Wenckstern, H. Schmidt, G. Biehne, H. Hochmuth, M. Lorenz, and M. Grundmann, Physica B 401-402, 378 (2007). 